\title{
LIMBAL TRANSPLANTATION IN THE MANAGEMENT OF CHRONIC CONTACT-LENS-ASSOCIATED EPITHELIOPATHY
}

\author{
CHRISTOPHER JENKINS, STEPHEN TUFT, CHRISTOPHER LIU and ROGER BUCKLEY \\ London
}

\begin{abstract}
SUMMARY
We describe the clinical management of 6 patients who developed a chronic corneal epitheliopathy 1-18 years after commencing soft contact lens wear. All had a history of exposure to thiomersal in contact lens fluids. The corneal changes were characterised by epithelial haze and superficial stromal vascularisation which extended from the limbus towards the visual axis. Five patients were observed for a minimum of 18 months after stopping contact lens wear before undergoing limbal transplantation. A good result was obtained in 1 patient who had worn a contact lens in one eye only. Recurrent epithelial changes were observed on the recipient eyes of the remaining patients who had previously worn contact lenses bilaterally, and in 1 patient epithelial haze also developed adjacent to the donor site in the previously clinically normal donor eye. All 5 patients experienced an improvement in symptoms post-operatively but in 2 patients the visual acuity later deteriorated because of epithelial irregularity. The sixth patient has not had surgery. We conclude that limbal stem cell dysfunction in chronic contact-lens-associated epitheliopathy may be subclinical and that autograft transplantation in bilaterally exposed patients may fail to restore the epithelial phenotype of the host eye whilst jeopardising the epithelial integrity of the donor eye by depleting its stem cell reserve.
\end{abstract}

The adverse effects of contact lenses on the cornea are typically reversible when contact lens wear is stopped. Several authors, however, have described chronic ocular surface changes which have failed to resolve on discontinuing lens wear. ${ }^{1-3}$ The corneas of these patients appear to be surfaced with conjunctivally derived epithelium. Kenyon and Tseng ${ }^{2}$ demonstrated the presence of goblet cells on the corneal surface of one case and suggested that

From: Moorfields Eye Hospital, London, UK.

Correspondence to: R. J. Buckley, The Contact Lens and Prosthesis Department, Moorfields Eye Hospital, City Road, London EC1V 2PD, UK. the pathogenesis of this condition may be related to a disorder of corneal epithelial stem cells, which are known to be located in limbal basal epithelium. ${ }^{4-6}$ Similar changes can be produced experimentally by surgical excision of the limbus ${ }^{7}$ and clinically after anterior segment surgery involving major resection of limbal tissue. Limbal autograft transplantation has been used to treat chronic contact-lens-associated epitheliopathy with apparent success. ${ }^{2,3}$ The procedure relies on harvesting normal limbal conjunctival tissue from the unaffected eye. When transplanted to the affected eye, stem cell replication and differentiation increases the corneal epithelial population with restoration of the corneal surface.

This paper describes the clinical findings in 6 patients with chronic contact-lens-associated epitheliopathy, 5 of whom were treated with limbal transplantation. In contrast to previous reports, post-operative deterioration of both the host and donor corneal surface was observed in some patients exposed bilaterally to thiomersal, which we attribute to a pre-existing subclinical stem cell dysfunction of the donor limbus.

\section{PATIENTS AND METHODS}

Six patients with sore, red eyes and blurred vision associated with contact lens wear were examined. Soft contact lenses had been worn from 1 to 18 years, and all patients had used cleaning and soaking solutions containing thiomersal (see Table I). On examination they were found to have hazy epithelium extending centrally from the limbus, with associated irregular astigmatism and superficial stromal vascularisation. None of the patients had evidence of tear dysfunction.

In 1 case, a soft contact lens had been worn in only one eye. In 2 cases the findings were apparently unilateral despite bilateral exposure, and in the remaining 3 the symptoms and signs were bilateral but asymmetrical. When at least 18 months without contact lenses had elapsed and no improvement in the clinical condition had 
Table I. Summary of case histories

\begin{tabular}{|c|c|c|c|c|c|c|c|c|}
\hline $\begin{array}{l}\text { Case } \\
\text { no. }\end{array}$ & $\begin{array}{c}\text { Age } \\
\text { and sex }\end{array}$ & $\begin{array}{c}\text { Thiomersal } \\
\text { concentration } \\
\text { of care systems }\end{array}$ & $\begin{array}{l}\text { Duration of } \\
\text { soft contact } \\
\text { lens wear }\end{array}$ & $\begin{array}{l}\text { Unilateral } \\
\text { or bilateral }\end{array}$ & $\begin{array}{c}\text { RVA at } \\
\text { initial visit }\end{array}$ & $\begin{array}{l}\text { LVA at } \\
\text { initial visit }\end{array}$ & $\begin{array}{l}\text { Period without } \\
\text { contact lens wear } \\
\text { prior to surgery }\end{array}$ & $\begin{array}{l}\text { Follow-up from } \\
\text { initial consultation } \\
\text { (years) }\end{array}$ \\
\hline 1 & $28 \mathrm{~F}$ & $0.001 \%$ & $\begin{array}{l}3 \text { years both } \\
\text { eyes }\end{array}$ & $\begin{array}{l}\text { Unilateral pre- } \\
\text { operatively }\end{array}$ & $6 / 9-3$ & $6 / 24$ & 27 months & 4 \\
\hline 2 & $35 \mathrm{M}$ & $0.002 \%$ & $\begin{array}{l}3 \text { years in } \\
\text { left eye only }\end{array}$ & Unilateral & PL & $<6 / 60$ & 2 years & 3 \\
\hline 3 & $23 \mathrm{~F}$ & $0.002 \%$ & $\begin{array}{l}2 \text { years both } \\
\text { eyes }\end{array}$ & $\begin{array}{l}\text { Bilateral; right } \\
\text { worse than left }\end{array}$ & $6 / 36$ & $6 / 6$ & 7 years & 9 \\
\hline 4 & $33 \mathrm{~F}$ & $0.001 \%$ & $\begin{array}{l}1 \text { year both } \\
\text { eyes }\end{array}$ & Unilateral & $6 / 9+3$ & $\mathrm{CF}$ & 7 years & 3 \\
\hline 5 & $31 \mathrm{~F}$ & $0.002 \%$ & $\begin{array}{l}8 \text { years both } \\
\text { eyes }\end{array}$ & $\begin{array}{l}\text { Bilateral; left } \\
\text { worse than right }\end{array}$ & $6 / 36$ & $\mathrm{CF}$ & 18 months & 4 \\
\hline 6 & $35 \mathrm{~F}$ & $0.002 \%$ & $\begin{array}{l}18 \text { years } \\
\text { both eyes }\end{array}$ & $\begin{array}{l}\text { Bilateral; left } \\
\text { worse than right }\end{array}$ & $6 / 6$ & $6 / 6$ & NS & 3 \\
\hline
\end{tabular}

VA, visual acuity; PL, perception of light; CF, counting fingers; R, right; L, left; M, male; F, female; NS, no surgery.

been observed, limbal transplantation was performed as previously described. ${ }^{2}$

\section{Case 1}

A 28-year-old Caucasian woman had successfully worn soft contact lenses in both eyes for myopia between 1982 and 1985, when she stopped because of discomfort. When examined in 1988, the visual acuities were 6/9-3 in the right eye and $6 / 24$ in the left. The right cornea appeared normal, but the epithelium of the left eye was hazy and there was superficial stromal scarring and peripheral vascularisation. Thiomersal hypersensitivity was suspected and the patient advised to await resolution. There was no change in the appearance of the cornea after 15 months' observation and in April 1990 limbal autograft transplantation was carried out from the clinically normal right eye to the affected left eye. The cornea was completely reepithelialised after 8 days, and after a month the visual acuity of this eye had improved to $6 / 12$ with spectacles. Three months post-operatively, however, abnormal epithelium was observed to have encroached from the superior limbus to the visual axis of the left eye, reducing the visual acuity to $6 / 60$. A trial of topical retinoic acid $0.05 \%$ had no beneficial effect and was discontinued after 2 months because of discomfort. Thirteen months postoperatively an area of abnormal epithelium was noted extending $3 \mathrm{~mm}$ from the superior limbus of the donor eye, but this has not subsequently progressed and the visual acuity in this eye remains 6/9-3 (Fig. 1).

\section{Case 2}

A 43-year-old Caucasian male had worn a soft contact lens on his left eye for 3 years. He had never worn a contact lens on the right eye, the vision in this eye being perception of light following retinal detachment surgery. He presented in February 1988 with pain and decreased vision in the left eye. On examination, the visual acuity of the left eye was less than $6 / 60$. The corneal epithelium was hazy and there was vascularisation of the superficial stroma. A silicone rubber therapeutic lens improved the left visual acuity to $6 / 9$, but was not tolerated for more than 1 hour at a time. No improvement was observed on follow-up over 18 months, and in September 1989 the patient underwent limbal autograft transplantation from the right to the left eye. Re-epithelialisation was complete after 10 days. When reviewed 1 month post-operatively, the patient achieved 6/9 with spectacles and the eye was more comfortable. The peripheral vessels had become inactive, although some scarring at the level of Bowman's layer had persisted inferiorly. The patient was lost to follow-up 14 months after surgery.

\section{Case 3}

A 23-year-old Caucasian woman had worn soft contact lenses for myopia for 2 years before she noticed that the vision of both eyes had become cloudy. This was associated with soreness, photophobia and watering. Her left eye improved 3 weeks after stopping contact lens wear, but the right eye remained photophobic and its vision blurred. When examined a year later, the visual acuities were $6 / 60$ in the right eye and 6/6 in the left eye. On slit lamp examination, the right eye was noted to have whorls of irregular, hazy epithelium with Salzmann-like changes. There was superficial vascularisation of the cornea peripherally but the stroma was clear. The left eye had abnormal epithelium over both the upper and lower third of the corneal surface. These signs were unchanged when in November 1990 she underwent limbal autograft transplantation from

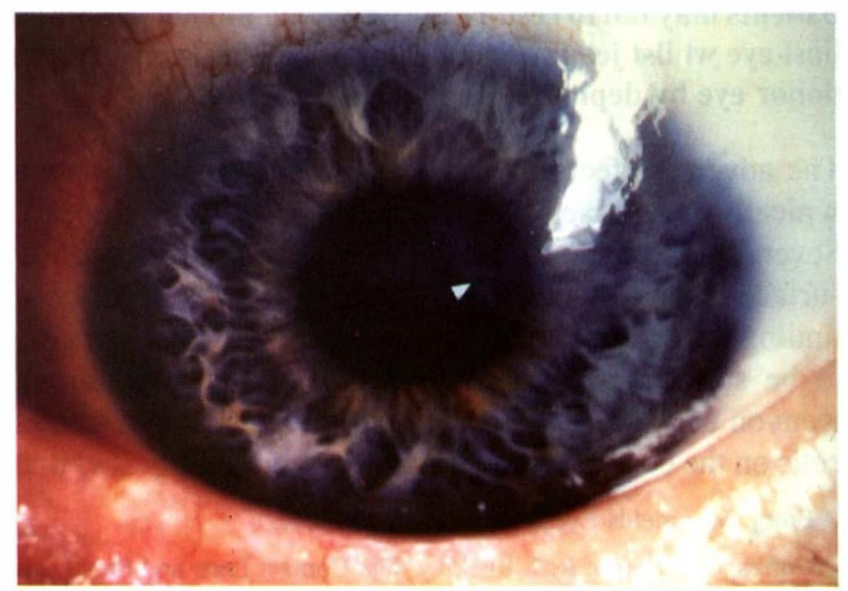

Fig. 1. Case 1. Post-operative appearance of cornea of donor eye, RVA 6/9. Note the irregular light reflex and the interface between normal and abnormal corneal epithelium (arrowhead). 
the left to the right eye, the conjunctiva being harvested from the nasal and temporal limbus. Re-epithelisation took 14 days and at 1 month post-operatively the corrected visual acuity of the right eye had improved to 6/18. At 3 months, however, the epithelium of this eye had again become irregular, with vortex and fine arcuate punctate epithelial keratitis, and the visual acuity had dropped to $6 / 36$. Only a small area of normal epithelium remained which was located adjacent to the inferior graft. Anterior stromal opacities were present centrally by 9 months but there was no vascularisation of the cornea. No changes in the appearance of the epithelium of the donor eye have been noted.

\section{Case 4}

A 33-year-old Asian woman had started wearing soft contact lenses for hypermetropia in 1983. After 1 year she developed soreness, watering and photophobia in both eyes and noticed that her vision had deteriorated. On discontinuing lens wear the vision of the right eye improved but that of the left remained poor, and the symptoms persisted. When referred in 1990, visual acuities were $6 / 9+3$ in the right eye and counting fingers $(\mathrm{CF})$ in the left. The right cornea was clinically normal but the epithelium of the left cornea was abnormal and a superficial fibrovascular membrane extended on to the cornea for 3-4 mm. Topical retinoic acid was commenced but discontinued after 3 months when the patient developed an epithelial defect. In September 1991 she underwent limbal autograft transplantation from the right to the left eye (Fig. 2). Reepithelialisation of the left cornea was complete after 14 days, and the visual acuity of this eye improved to $6 / 18$. Two months post-operatively there was slight encroachment of conjunctival epithelium for $2 \mathrm{~mm}$ at the inferonasal and inferotemporal margins on either side of the lower limbal graft with sub-epithelial haze in these areas (Fig. 3). No further progression has been observed. The acuity of the left eye is currently $6 / 9+3$ and the donor eye remains clinically normal.

\section{Case 5}

A 28-year-old Caucasian woman had worn soft contact

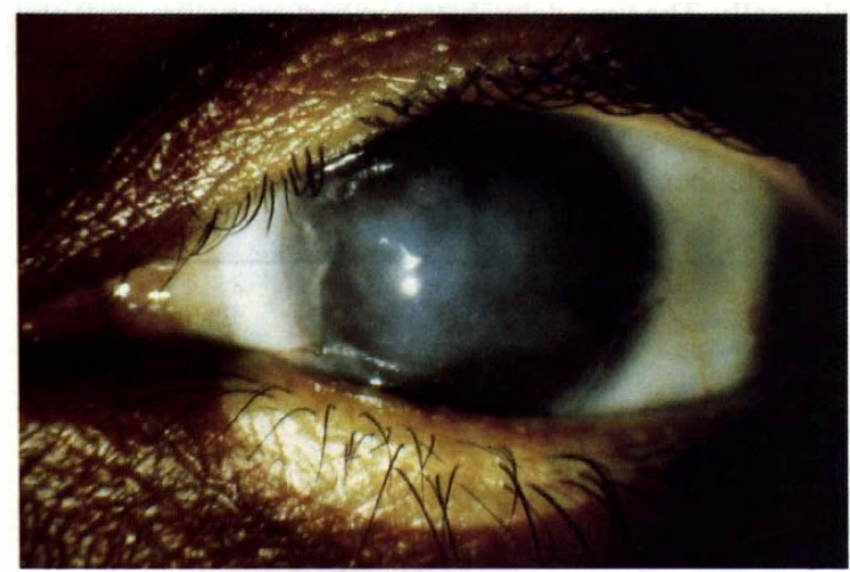

Fig. 2. Case 4. Pre-operative appearance of the left cornea. LVA CF. lenses for 7 years for the correction of hypermetropia. In June 1989 she developed pain and photophobia of her left eye caused by an epithelial defect. Thiomersal sensitivity was suspected and contact lens wear discontinued. Her symptoms persisted and when examined in January 1990, the visual acuity was $6 / 9$ in the right eye and $6 / 36$ in the left eye. There was superior subepithelial opacification for 1-2 mm adjacent to the limbus of the right eye. In the left eye she had an epithelial defect superonasally with adjacent superficial corneal vascularisation and irregular epithelium over the remaining corneal surface. In October 1991 she developed a persistent epithelial defect of the right cornea accompanied by a reduction in visual acuity of this eye. In February 1992 the visual acuities of the right and left eyes were 6/36 and CF respectively. The entire corneal surface of both eyes was abnormal, with Salzmann-like nodules and superficial stromal vascularisation. An acceptably close HLA match with the patient's brother having been established, allograft transplantation of limbal tissue from the brother to the patient's left eye was performed in May 1992. Epithelialisation of the cornea was complete after 10 days. One month post-operatively, the new epithelium appeared to be failing. The eye was treated with intensive topical steroids, and by 3 months the epithelium appeared healthy. By November 1992 the spectacle acuity of the left eye was 6/12 and this has subsequently improved to $6 / 9$. The right visual acuity remains at $6 / 36$. The epithelium overlying the superior corneal surface of the left eye is rough and irregular for $3 \mathrm{~mm}$ from the superior limbus, whilst some anterior stromal haze remains centrally over the visual axis.

\section{Case 6}

A 35-year-old myopic Caucasian woman had successfully worn daily-wear soft contact lenses for 18 years. She presented in January 1990 with a 6-month history of intermittent soreness and redness in her left eye. On examination, the visual acuity of both eyes was $6 / 6$ and she was noted to have an epitheliopathy most marked in the left eye adjacent to the superior limbus, with punctate

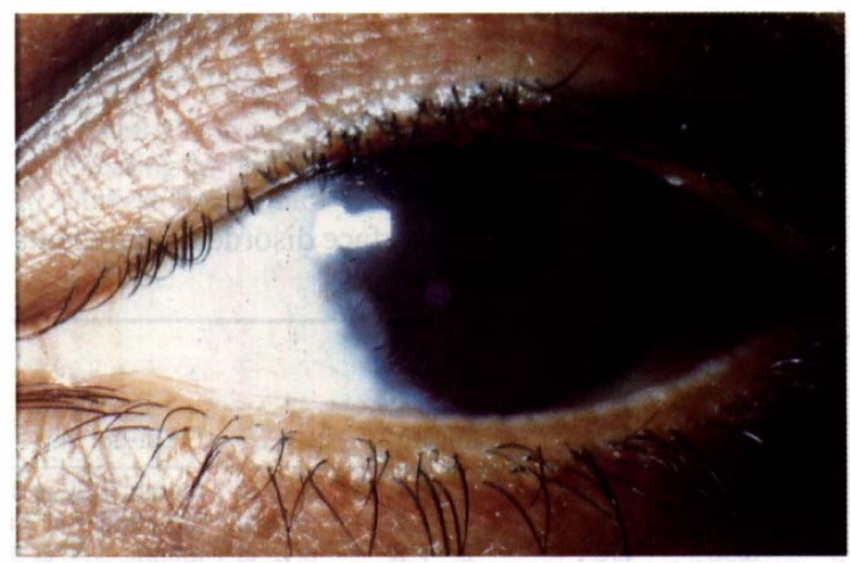

Fig. 3. Case 4. Appearance of the left cornea 8 months after limbal autograft transplantation. LVA 6/9. Note the marked improvement in corneal clarity with insignificant corneal epithelial haze adjacent to the limbus inferonasally (arrow). 


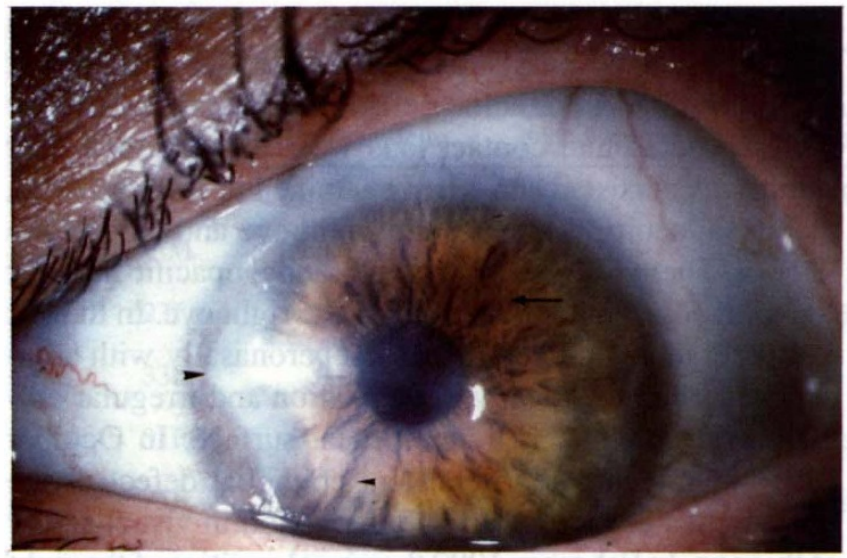

Fig. 4. Case 6. Thirty months after discontinuing contact lens wear there is patchy epithelial haze (small arrowhead) with areas of relatively normal corneal epithelium (arrow). Note the persistent Salzmann-like change adjacent to the nasal limbus (large arrowhead).

fluorescein staining and hazy underlying stroma. Thiomersal sensitivity was suspected and a challenge with $0.005 \%$ thiomersal solution was positive after two drops. Her symptoms subsided on stopping contact lens wear and in February 1990 she was advised that she could wear soft contact lenses in conjunction with thiomersal-free solutions. However, the vision in the left eye deteriorated to $6 / 12$ and she was noted to have a sheet of abnormal epithelium extending $6 \mathrm{~mm}$ from the upper limbus over the visual axis. Contact lens wear was again discontinued and the vision initially improved to $6 / 6$ before deteriorating again. Over the next 6 months her ocular symptoms and visual acuity fluctuated according to the type of epithelium covering the visual axis. Topical retinoic acid was prescribed, but was soon discontinued by the patient because of discomfort and the lack of any improvement in her vision. By October 1990 the vision in the left eye was $3 / 60$, there was no normal corneal epithelium, and areas of Salzmann-like change were noted. The right eye throughout this period showed changes adjacent to the superior limbus, with raised opaque epithelium staining in a vortex pattern with fluorescein. When reviewed in September 1992, 30 months after discontinuing contact lens wear, the patient was free of symptoms and the visual acuity of the left eye had improved to 6/24 (Fig. 4).

\section{DISCUSSION}

We describe a chronic ocular surface disorder in 6 patients who had worn soft contact lenses. All gave a history of exposure to thiomersal, an antimicrobial agent once commonly found in soft contact lens care systems. In the patients affected bilaterally, the less-affected eye showed a strong resemblance to the findings described by Wright and Mackie. ${ }^{8}$ Thiomersal challenge was positive in 1 case but was not used in the others because of the possible risk of precipitating further deterioration of the corneal surface. However, conjunctival thiomersal challenge was positive in 2 earlier cases of chronic contact-lens-associated epitheliopathy seen at this hospital. ${ }^{9}$

Contact lens wear and exposure to thiomersal were discontinued in all of our cases. No improvement was observed in 5 patients in up to 7 years' follow-up. In case 6 , however, the visual acuity improved from $3 / 60$ to $6 / 24$ over a period of 30 months. Retinoic acid has been reported to increase the rate of corneal epithelial wound healing, ${ }^{10,11}$ and although there is evidence that it promotes transdifferentiation of conjunctivally derived epithelium in models of limbal stem cell deficiency, ${ }^{12-14}$ there is no evidence of an influence on transdifferentiation of conjunctival to corneal epithelial phenotypes. Nevertheless, it was prescribed for 3 of our cases. No improvement of the ocular surface was observed in the periods for which the drops were tolerated.

Five cases underwent limbal transplantation and obtained symptomatic relief as early as 1 week postoperatively - an improvement paralleled by repopulation of the ocular surface with apparently normal corneal epithelium. In case 2 , the patient had worn a contact lens on one eye only. He had an excellent result with a return to his previous acuity and normalisation of the ocular surface. Late post-operative changes in the epithelial phenotype on both the host (4 patients) and donor (1 patient) corneal surfaces were observed in the remaining patients, all of whom had worn contact lenses on both eyes (see Table II). These changes may have been caused by failure of limbal stem cell replication, preventing renewal not only of the host but also of the donor limbal stem cell population. Although epithelial metaplasia in the donor eye has been predicted as a possible complication of limbal transplantation, ${ }^{15}$ we believe this to be the first case to be reported clinically. The time delay between harvesting the graft and the development of epithelial abnormalities on the donor cornea may relate to the life span of the basal corneal epithelial cells, which can divide rapidly but only for a limited number of times before terminal differentiation.

Table II. Results of limbal transplantation

\begin{tabular}{|c|c|c|c|c|c|c|c|}
\hline $\begin{array}{l}\text { Case } \\
\text { no. }\end{array}$ & RVA & LVA & $\begin{array}{c}\text { Limbal } \\
\text { autograft }\end{array}$ & Post-op. VA & $\begin{array}{l}\text { Post-op. } \\
\text { follow-up } \\
\text { (months) }\end{array}$ & $\begin{array}{l}\text { Encroachment } \\
\text { of conjunctival } \\
\text { epithelium on } \\
\text { recipient cornea }\end{array}$ & $\begin{array}{c}\text { Encroachment of } \\
\text { conjunctival } \\
\text { epithelium on }\end{array}$ \\
\hline 1 & $6 / 9-3$ & $6 / 24$ & $\mathrm{R} \rightarrow \mathrm{L}$ & $6 / 12$ at 1 month, $6 / 60$ at 3 months & 30 & At 3 months superiorly & At 13 months \\
\hline 2 & PL & $<6 / 60$ & $\mathrm{R} \rightarrow \mathrm{L}$ & $6 / 18$ at 1 month, $6 / 9$ at 3 months & 36 & No & No \\
\hline 3 & $6 / 36$ & $6 / 6$ & $\mathrm{~L} \rightarrow \mathrm{R}$ & $6 / 18$ at 1 month, $6 / 36$ at 3 months & 24 & At 3 months superiorly & No \\
\hline 4 & $6 / 9+3$ & $\mathrm{CF}$ & $\mathrm{R} \rightarrow \mathrm{L}$ & $6 / 18$ at 1 month, $6 / 9$ at 3 months & 16 & At 1 month inferiorly & No \\
\hline 5 & $6 / 36$ & $\mathrm{CF}$ & Allograft & $\begin{array}{l}\mathrm{CF} \text { at } 1 \text { month, } 6 / 18 \text { at } 3 \text { months, } \\
6 / 9 \text { at } 10 \text { months }\end{array}$ & 12 & At 1 month superiorly & No (allograft) \\
\hline
\end{tabular}

VA, visual acuity; L, left; R, right; PH, pinhole; CF, counting fingers; PL, perception of light. 
Interestingly, Kinoshita ${ }^{16}$ has demonstrated that donor epithelium survives for approximately 1 year after penetrating keratoplasty, which is similar to the interval before decompensation of the donor cornea in case 1 .

The pre-operative corneal changes of our patients were most marked adjacent to the superior limbus. This was also the site of post-operative conjunctival ingrowth on the host cornea in cases 1, 3 and 5 and the donor cornea in case 1 (even though in this last case the graft had been harvested nasally and temporally). Initial location of corneal epithelial changes adjacent to the superior and inferior limbus has been observed in aniridia, another condition in which limbal stem cell failure is thought to occur. ${ }^{17}$ The onset and progression of contact-lens-associated epitheliopathy may therefore depend not only on the degree of stem cell failure, but also on physical factors such as pressure from the eyelids or contact lens. It has been found that repeated removal of the limbal epithelium caused accelerated conjunctival epithelial ingrowth in experimental conditions of partial stem cell loss. ${ }^{18}$

We have experienced complications to both the host and donor eye using limbal autograft transplantation for chronic contact-lens-associated epitheliopathy. These varied considerably in severity. Cases 1 and 3 lost vision in the grafted eye, whereas cases 2, 4 and 5 obtained excellent functional improvement (Figs. 2, 3). We suggest that limbal stem cell failure may be quite advanced before changes become clinically apparent and stem cell dysfunction may be present in grafts obtained from clinically normal eyes. It is difficult to predict the long-term results of autograft transplantation in these patients. The use of an unrelated donor allograft theoretically obviates this problem, while simultaneously imposing the new possibility of rejection. Tseng has grafted limbal tissue from cadaver eyes with only a $30 \%(3 / 10)$ rejection rate, ${ }^{15}$ and in 2 of these cases the rejection episode responded to oral cyclosporin. An alternative approach is the use of live-related or HLA-matched limbal tissue for allograft transplantation. We believe that these latter procedures should be given serious consideration in cases of bilateral epitheliopathy and in patients who have had an unfavourable response to conventional autografting methods.

Key words: Contact lenses, Corneal epithelium, Limbal autograft transplantation, Limbal stem cells, Thiomersal.

\section{REFERENCES}

1. Bloomfield SE, Jakobiec FA, Theodore FH. Contact lens induced keratopathy. Ophthalmology 1984;91:290-4.
2. Kenyon KR, Tseng SCG. Limbal autograft transplantation for ocular surface disorders. Ophthalmology 1989;96: 709-23.

3. Clinch TE, Goins KM, Cobo M. Treatment of contact lensrelated ocular surface disorders with autologous conjunctival transplantation. Ophthalmology 1992;99:634-8.

4. Schermer A, Galvin S, Sun T-T. Differentiation related expression of a major $64 \mathrm{~K}$ corneal keratin in vivo and in culture suggests limbal location of corneal epithelial stem cells. J Cell Biol 1986; 103:49-62.

5. Cotsarelis G, Cheng S-Z, Dong G, et al. Existence of slowcycling limbal epithelial basal cells that can be preferentially stimulated to proliferate: implications on epithelial stem cells. Cell 1989;57:201-9.

6. Zieske JD, Bukusaglu G, Yankauckas MA. Characterisation of a potential marker of corneal epithelial stem cells. Invest Ophthalmol Vis Sci 1992;33:143-52.

7. Huang AJW, Tseng SCG. Corneal epithelial wound healing in the absence of limbal epithelium. Invest Ophthalmol Vis Sci 1991;32:96-105.

8. Wright P, Mackie I. Preservative-related problems in soft contact lens wearers. Trans Ophthalmol Soc UK 1982;102: 3-6.

9. Wilson-Holt N, Dart JKG. Thiomersal keratoconjunctivitis: frequency, clinical spectrum and diagnosis. Eye 1989;3: 581-7.

10. Smolin G, Okumoto M, Friedlaender M. Tretinoin and corneal epithelial wound healing. Arch Ophthalmol 1979;96: 545-6.

11. Ubels JL, Edelhauser HF, Austin KH. Healing of experimental corneal wounds treated with topically applied retinoids. Am J Ophthalmol 1983;95:353-8.

12. Tseng SCG, Hirst LW, Farazdaghi M, Green WR. Inhibition of conjunctival transdifferentiation by topical retinoids. Invest Ophthalmol Vis Sci 1987;28:538-42.

13. Tseng TSG, Farazdaghi M. Reversal of conjunctival transdifferentiation by topical retinoic acid. Cornea 1988;7: 273-9.

14. Kruse FE, Chen JJY, Tsai RJF, Tseng SCG. Conjunctival transdifferentiation is due to the incomplete removal of limbal basal epithelium. Invest Ophthalmol Vis Sci 1990;31: 1903-13.

15. Tseng SCG, Tsai RJF. Limbal transplantation for ocular surface reconstruction: a review. Fortschr Ophthalmol 1990; 88:236-42.

16. Kinoshita S, Friend J, Thoft RA. Sex chromatin of donor corneal epithelium in rabbits. Invest Ophthalmol Vis Sci 1981;21:434.

17. Mackman G, Brightbill FS, Optiz JM. Corneal changes in aniridia. Am J Ophthalmol 1979;87:497-502.

18. Chen JY, Tseng SCG. Abnormal corneal epithelial wound healing in partial-thickness removal of limbal epithelium. Invest Ophthalmol Vis Sci 1991;32:2219-33. 